\title{
Remarkable Phosphine-Effect on the Intramolecular Aldol Reactions of Unsaturated 1,5-Diketones: Highly Regioselective Synthesis of Cross-Conjugated Dienones
}

\author{
Reema K. Thalji ${ }^{\dagger}$ and William R. Roush ${ }^{\ddagger}{ }^{*}$ \\ $\dagger$ Department of Chemistry, University of Michigan, Ann Arbor, MI 48109-1055 \\ $\$$ Department of Chemistry, Scripps-Florida, Jupiter, FL 33485
}

As part of a target-oriented synthetic study, we were interested in developing selective syntheses of linear- and cross-conjugated dienones via aldol cyclizations of diketones (eq 1). Methods for the regioselective aldol reaction of such diketones are scarce, especially in cases where the steric environments of the two carbonyl groups are very similar. ${ }^{1}$ 1,5-Diketones such as $\mathbf{1}$ were of interest because they are readily prepared via the phosphine-catalyzed intramolecular vinylogous Morita-Baylis-Hillman (MBH) cyclization of bis- $\alpha, \beta$-unsaturated carbonyl compounds, ${ }^{2}$ a reaction that was developed simultaneously in the Krische group ${ }^{3}$ and in our laboratory 4,5 . During the course of our studies of the vinylogous MBH reaction, competitive intramolecular aldol cyclizations were observed for vinylogous $\mathrm{MBH}$ products 1 bearing enolizable carbonyl units when these reactions were performed in protic solvents such as $t$-Amyl alcohol. ${ }^{4 \mathrm{a}}$ This observation is consistent with the notion that the aldol reactions are catalyzed by alkoxide generated via deprotonation of alcoholic solvent by the zwitterionic phosphonium enolate intermediates. ${ }^{6}$ During efforts to optimize this tandem $\mathrm{MBH} /$ aldolization process, we discovered and report herein remarkable and unprecedented regioselectivity in the aldol step, resulting in extremely high selectivity for the less stable crossconjugated dienones. We also provide evidence for the involvement of the phosphonium unit of the phosphine-enone Michael adduct (e.g., 6) in controlling the regiochemistry of these reactions.

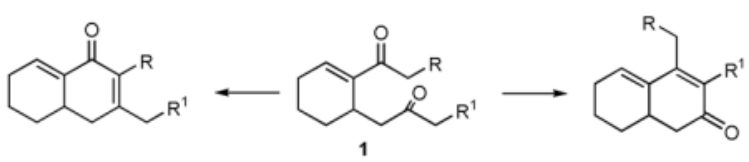

Symmetrical bisenone 2 was selected for initial reaction development studies (Table 1). The cyclization of $\mathbf{2}$ at room temperature in the presence of 1 equiv of $\mathrm{PBu}_{3}$ in $\mathrm{MeOH}$ as the solvent produced regioisomeric aldol condensation products 4 and 5 with excellent selectivity (4:5 $=94: 6$ ) for the cross-conjugated isomer 4 (entry 1). The $\mathrm{Bu}_{3} \mathrm{P}$ loading can be decreased to 0.25 equiv if the reaction is performed at $60^{\circ} \mathrm{C}$, and the selectivity is only slightly lower $(4$ : $5=93: 7$, entry 2). Unfortunately, these products were contaminated with inseparable adducts of MeOH-Michael addition to $\mathbf{4}$ and $\mathbf{5}^{7}$ Use of $t$-AmylOH as the reaction solvent resulted in inefficient aldol condensation (entry 3), while use of $i$-PrOH gave a very clean, high yield $(80 \%)$ of products, but with poor selectivity $(4: 5=71: 29$, entry 4$)$. Remarkably, however, 
use of $\mathrm{CF}_{3} \mathrm{CH}_{2} \mathrm{OH}$ as solvent for the tandem reaction gave clean aldol condensation product with exclusive selectivity for $\mathbf{4}$; isomer $\mathbf{5}$ was undetected by ${ }^{1} \mathrm{H}$ NMR analysis (entry 5). $\mathrm{PMe}_{3}$ can also be used to promote this reaction with identical selectivity to that obtained using $\mathrm{PBu}_{3}$ (entry 6).

The very high regioselectivity for $\mathbf{4}$ in these reactions was unexpected. A priori, we had anticipated that poor kinetic selectivity would occur in the aldol step due to the similarity in $\mathrm{pK}_{\mathrm{a}}$ and steric environment of the two ketone units in intermediate $\mathbf{3}$; moreover, the linearlyconjugated isomer 5 was expected to predominate if the reaction was subject to thermodynamic control. ${ }^{1}$ Therefore, it is noteworthy that we observe such high regioselectivity and that the reaction is highly selective for the less stable cross-conjugated isomer. ${ }^{8}$ We postulate that the high degree of selectivity derives from an interaction between the phosphonium unit and the adjacent carbonyl in intermediate 6 . This would increase the acidity of the $\beta$-phosphoniumsubstituted methyl ketone such that it is deprotonated regioselectively by the alkoxide $(\mathbf{6} \rightarrow \mathbf{7}$, eq 2). ${ }^{9}$

$\mathrm{RO}^{-}$<smiles>[R7][PH2+]C1CCCC(CC(C)=O)C1C(C)=O</smiles>
6
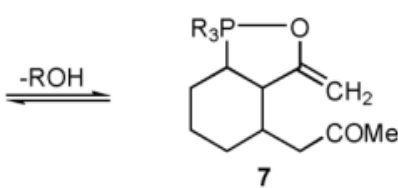

Experimental evidence for this phosphine effect was obtained by subjecting $\mathrm{MBH}$ product 3 to a catalytic amount of $\mathrm{CF}_{3} \mathrm{CH}_{2} \mathrm{ONa}$ in $\mathrm{CF}_{3} \mathrm{CH}_{2} \mathrm{OH}$ (eq 3). No reaction was observed, indicating that $\mathrm{CF}_{3} \mathrm{CH}_{2} \mathrm{ONa}$ is not basic enough to deprotonate 3 in the absence of phosphine. While 3 undergoes efficient aldol cyclization when treated with $i$-PrONa (eq 4), the selectivity $(\mathbf{4}: \mathbf{5}=18: 82)$ is opposite to that observed using $\mathrm{PBu}_{3} / i-\mathrm{PrOH}(\mathbf{4}: \mathbf{5}=71: 29)$. Furthermore, treatment of $\mathbf{3}$ with $\mathrm{PBu}_{3}$ in $\mathrm{CF}_{3} \mathrm{CH}_{2} \mathrm{OH}$ affords $\mathbf{4}$ exclusively (eq 5), demonstrating that $\mathbf{3}$ is a viable intermediate in the conversion of $\mathbf{2}$ to 4 . These results support our proposal that 6 plays a key role in controlling the regioselectivity of the aldol step.

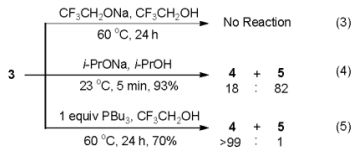

Other bisenone substrates cyclize to afford exclusively the cross-conjugated isomers (Table 2). Bisenone 8, bearing a shorter tether, cyclizes to dienone 9 in $76 \%$ yield (Table 2, entry 2). Substrate $\mathbf{1 0}$ can theoretically afford two vinylogous MBH adducts (c.f., 1), each of which in principle can cyclize to give two aldol regioisomers. Remarkably, $\mathbf{1 0}$ cyclized to afford only one out of four possible products (11) in 71\% yield (entry 3). Evidently, the vinylogous MBH cyclization of $\mathbf{1 0}$ occurs with selectivity that is consistent with initial phosphine addition to the least hindered enone, while the selectivity of the aldol step is governed by the phosphine effect outlined above.

Sterically differentiated bisenones $12,14,16$, and 18 (Table 2 , entries 7-10), which contain a hindered $\beta, \beta$-disubstituted enone, undergo efficient and selective MBH cyclization and subsequent aldol condensation to give the cross-conjugated products. Again, only one out of four possible products is formed. For these substrates, the optimal conditions involved use of 5 equiv of $\mathrm{PMe}_{3}$ in $t$-AmylOH at $80^{\circ} \mathrm{C}$; the $\mathrm{MBH}$ cyclization in these cases was unsuccessful using $\mathrm{CF}_{3} \mathrm{CH}_{2} \mathrm{OH}$ as solvent. In all cases, products bearing quaternary centers were generated in good yield (58-64\%). 
MBH product 20, which can be isolated from the cyclization of bisenone 18, undergoes phosphine-mediated aldol cyclization with the most hindered enolate serving as the nucleophile to generate isomer $\mathbf{1 9}$ (Scheme 1). Interestingly, a base-promoted aldol cyclization of $\mathbf{2 0}$ in the absence of phosphine results in a complete reversal of selectivity, and the linearly-conjugated isomer 21 is obtained in >95:5 selectivity. This example highlights the striking complementarity of the phosphine-mediated aldol condensation to a traditional aldol process.

In summary, we have discovered a phosphine-mediated intramolecular aldol cyclization of unsaturated diketones 1 that proceeds with extremely high levels of regioselectivity for the cross-conjugated bicyclic dienone products. The sense of regioselectivity observed in this reaction is unattainable using traditional aldol conditions, and is governed by the chemistry of the phosphine Michael adduct $\mathbf{6}$. Applications of this method to the synthesis of natural products will be reported in due course.

\section{Supplementary Material}

Refer to Web version on PubMed Central for supplementary material.

\section{Acknowledgements}

We thank the National Institutes of Health for financial support (GM26782) and a postdoctoral fellowship to R. K. T. (GM073325).

\section{References}

1. (a) For leading references on the regioselectivity of base-catalyzed aldol cyclizations of 1,4- and 1,5diketones, see: Singh RK, McCurry PM. J Org Chem 1974;39:2316. and Danishefsky S, Zimmer A. J Org Chem 1976;41:4059. For a review: (b)HeathcockCHHeathcockCHComprehensive Organic SynthesisPergamon PressNew York19912181

2. For selected reviews on the Morita-Baylis-Hillman reaction, see: (a) Basavaiah D, Rao AJ, Satyanarayana T. Chem Rev 2003;103:811. [PubMed: 12630854] (b) Kim JN, Lee KY. Curr Org Chem 2002;6:627. (c) Langer P. Angew Chem Int Ed 2000;39:3049. (d) Ciganek E. Org React 1997;51:201. (e) Drewes SE, Roos GHP. Tetrahedron 1988;44:4653. For a review of reactions involving phosphine organocatalysis: (f) Methot JL, Roush WR. Adv Synth Catal 2004;346:1035. For selected examples of the related Rauhut-Currier reaction, see: (g)RauhutMMCurrierHU.S. Patent, 3,074,9991963(h)McClureJDJU.S Patent 3,225,0831965 (i) Drewes SE, Emslie ND, Karodia N. Synthetic Commun 1990;20:1915. (j) Jenner G. Tetrahedron Lett 2000;41:3091.

3. (a) Wang LC, Luis AL, Agapiou K, Jang HY, Krische MJ. J Am Chem Soc 2002;124:2402. [PubMed: 11890765] (b) Agapiou K, Krische MJ. Org Lett 2003;5:1737. [PubMed: 12735765]

4. (a) Frank SA, Mergott DJ, Roush WR. J Am Chem Soc 2002;124:2404. [PubMed: 11890766] (b) Mergott DJ, Frank SA, Roush WR. Org Lett 2002;4:3157. [PubMed: 12201741] (c) Methot JL, Roush WR. Org Lett 2003;5:4223. [PubMed: 14572290]

5. For a related study: Brown PM, Kappel N, Murphy PJ. Tetrahedron Lett 2002;43:8707.

6. (a) Stewart IC, Bergman RG, Toste FD. J Am Chem Soc 2003;125:8696. [PubMed: 12862443] (b) Inanaga J, Baba Y, Hanamoto T. Chem Lett 1993:241. (c) Trost BM, Li CJ. J Am Chem Soc 1994;116:3167. (d) Couturier M, Ménard F, Ragan JA, Riou M, Dauphin E, Anderson BM, Ghosh A, Dupont-Gaudet K, Girardin M. Org Lett 2004;6:1857. [PubMed: 15151432]

7. Solvent mixtures of THF, MeCN, or and $\mathrm{MeOH}$ significantly reduced $\mathrm{CH}_{2} \mathrm{Cl}_{2}$ the amount of $\mathrm{MeOH}$ Michael adducts (from $20 \%$ to $3 \%$ ), but conversions and/or selectivities were lower in these solvent systems.

8. Isomers $\mathbf{4}$ and $\mathbf{5}$ do not equilibrate under the reaction conditions.

9. For known examples of structures related to 7, see: (a) Bentrude WG, Johnson WD, Khan WA. J Am Chem Soc 1972;94:923-932. (b) Arbuzov BA, Zoroastrova VM, Tudrii GA, Fuzhenkova AV. Bull Acad Sci USSR Div Chem Sci 1973;22:2513. (c) Aksnes G, Frøyen P. Acta Chem Scand 
1968;22:2347. (d) Ramirez F, Madan OP, Heller SR. J Am Chem Soc 1965;87:731. (e) Evans DA, Hurst KM, Takacs JM. J Am Chem Soc 1978;100:3467. 


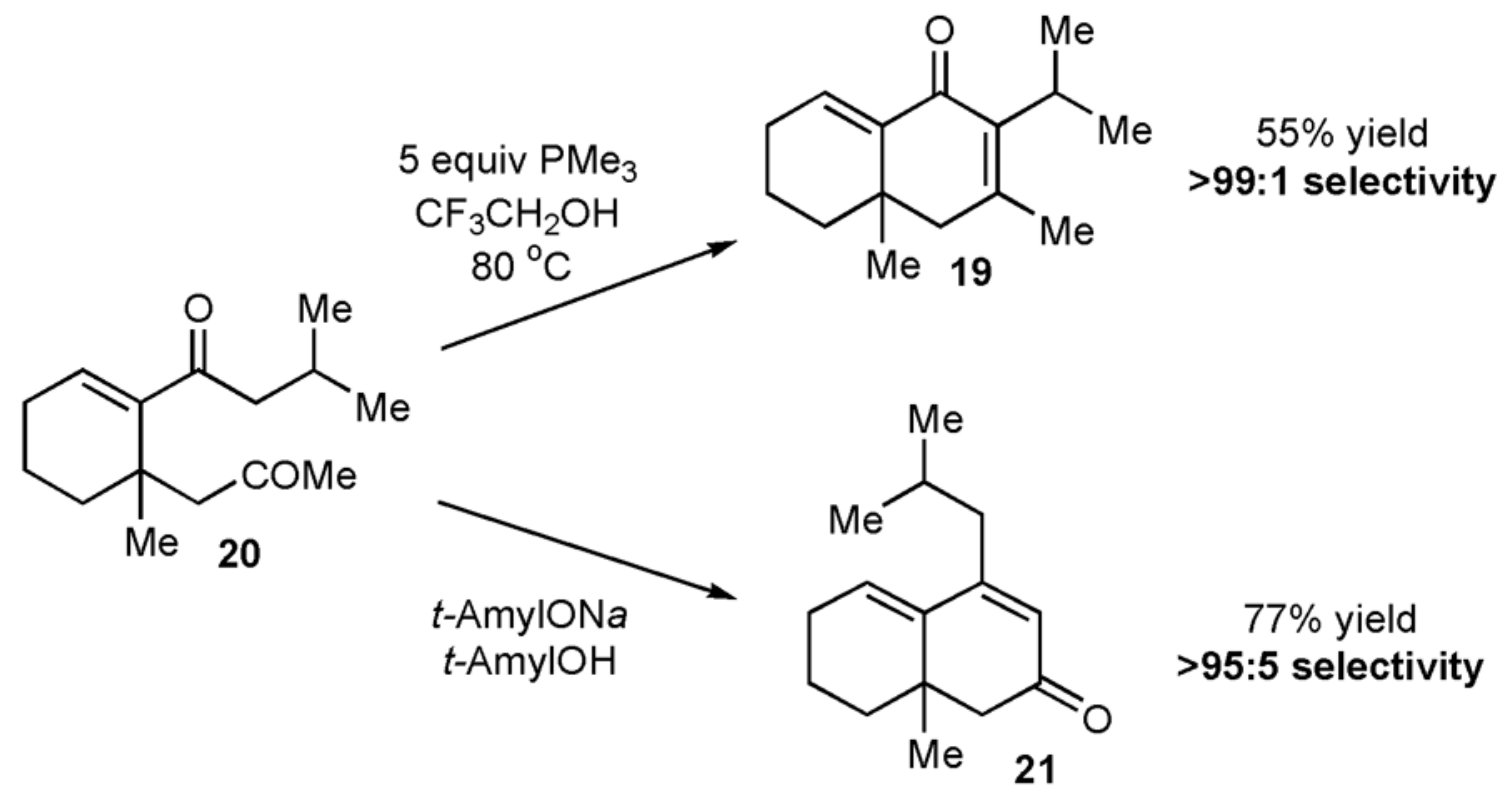

Scheme 1.

Synthesis of Cross-Conjugated or Linear Dienones 


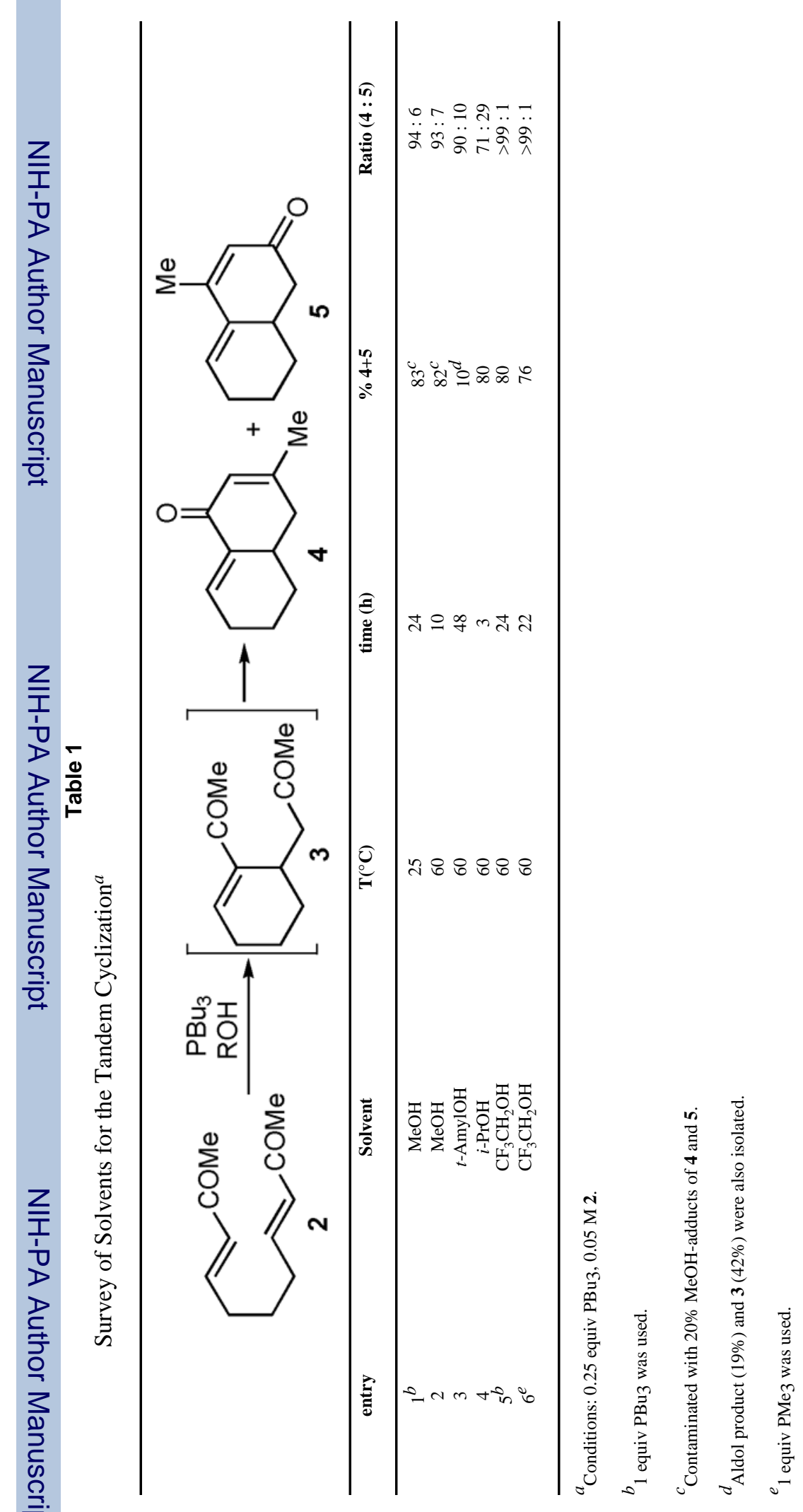




\section{Table 2}

Substrate Scope of the Tandem Cyclization

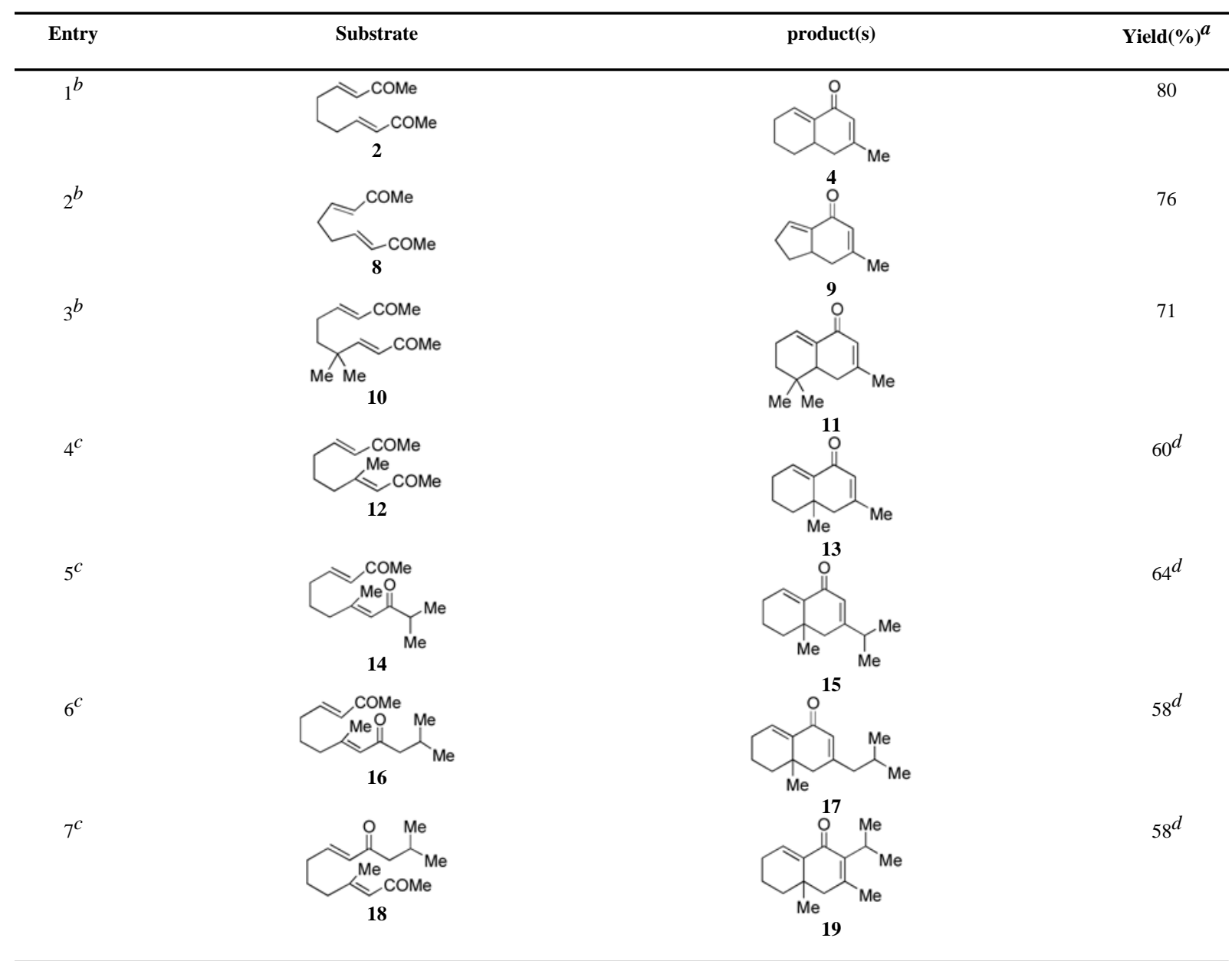

${ }^{a}$ The only product isomers detected by ${ }^{1} \mathrm{H}$ NMR analysis of the crude material are those indicated.

${ }^{b}$ Method A: 1 equiv $\mathrm{PMe}_{3}, 0.05 \mathrm{M}$ substrate in $\mathrm{CF}_{3} \mathrm{CH}_{2} \mathrm{OH}, 60{ }^{\circ} \mathrm{C}$.

${ }^{c}$ Method B: 5 equiv PMe3, $0.05 \mathrm{M}$ substrate in $t$ - AmylOH, $80^{\circ} \mathrm{C}$.

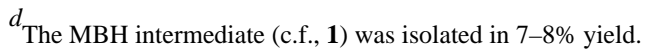

